\title{
DINÂMICA DE MERCADO E TRAJETÓRIA DE PRODUTORES EM FACE DO SISTEMA DE CLASSIFICAÇÃO DE VINHOS
}

\section{RESUMO}

O objetivo deste artigo é refletir sobre a relação entre os agentes econômicos e as instituições de mercado. Em específico, o artigo analisa como os produtores de vinhos na França reagem às rígidas classificações existentes no mercado de vinhos desse país. Partindo de um estudo de caso de dois produtores vinícolas franceses, o artigo discorre sobre dois conjuntos distintos de estratégias por eles adotados para maximizar seus lucros em um contexto de forte enquadramento institucional, que prima pela marca e qualidade do vinho atreladas à região a que pertencem. Como conclusão, o artigo destaca a importância da sociologia do agente para se compreender a dinâmica do mercado.

\section{Marie-France Garcia-Parpet}

Institut National de la Recherche Agronomique

ABSTRACT The purpose of this article is to discuss the relationship between economic agents and market institutions. More specifically, the article examines how wine producers in France respond to the severe classifications applied in the French wine market. Starting from a case study comprising two French wineries, this article analyzes two distinct sets of strategies adopted to maximize their profits in a context of heavy institutional framing, attaching special importance to wine quality and brand as related to the specific region where they belong. The article concludes emphasizing the importance of considering the agent-based sociological perspective for a better understanding of the market dynamics.

PALAVRAS-CHAVE Sociologia econômica, mercado, classificações de origem controlada, agentes econômicos, redes sociais. KEYWORDS Economic sociology, market, controlled origin classification, economic agents, social network. 


\section{INTRODUÇÃO}

Contra a "mão invisível" da teoria neoclássica, diversos autores ressaltaram as determinantes estruturais que influenciam os agentes econômicos. Insistem principalmente sobre o papel do Estado, assim como sobre as normas e classificações que apresentam uma diversidade que resulta da história, da ação das organizações sociais e dos interesses antagônicos presentes na sua elaboração. ${ }^{1}$ A literatura que analisa os fatos econômicos é muito discreta com relação ao caráter atomístico e intercambiável dos agentes econômicos conforme defendido pelo mainstream dos economistas.

Este artigo se propõe fazer uma reflexão sobre a relação entre os agentes econômicos e as instituições do mercado, principalmente as classificações. Assim, colcamos a seguinte questão: as classificações constituem um trunfo ou uma limitação para os produtores? Em outros termos, os produtores são forçados, segundo sua posição no espaço social e suas possibilidades econômicas, a modificar seus investimentos para se colocar em conformidade com as classificações existentes, ou para reforçá-las quando elas lhes são favoráveis, ou ainda, em caso contrário, para criar outras classificações? A análise dos agentes e de sua atitude em face das instituições é aqui o elemento complementar, porém essencial, para a compreensão da dinâmica dos mercados - entendidos como fenômenos sociais. Qual é a relação entre os produtores com essas classificações e quais são as estratégias que eles adotam para maximizar seus lucros? Para refletir sobre tais indagações, tomaremos como exemplo o caso dos vinhos franceses, num contexto de globalização. Produto de distinção social, caracterizado por efeitos econômicos e simbólicos importantes, o vinho francês é objeto de classificações sancionadas juridicamente ou não, forjadas ao longo da história. ${ }^{2}$

Contrariamente ao que ocorre nos países do Novo Mundo, onde a qualidade do vinho é designada pelo tipo de uva que permite a produção de um determinado vinho, ou ainda por certas marcas, o campo vinícola francês é constituído de tal maneira que as estratégias dos produtores são elaboradas por pertencerem ou não a uma "denominação de origem controlada" (DOC) [AOC, ou seja, appellation d'origine contrôlée $]^{3}$ e pela notoriedade da região onde estão situados. Os vinhos de denominação de origem controlada (ver quadro sobre os DOC) se opõem aos "vinhos de mesa" ["vins de table"] e, mais recentemente, aos "vinhos regionais" ["vins de pays"], estes últimos representando uma categoria relacionada à origem geográfica, mas cujos critérios de produção são menos rigorosos que aqueles de DOC. Os vinhos de DOC evocam a "qualidade", enquanto os demais vinhos evocam a idéia de um "vinho de massa". Entre os vinhos de DOC, figuram os mais prestigiosos, em especial os grands crus - categorias utilizadas para definir os Bordeaux mais renomados - adotados em diversas regiões. ${ }^{4}$ Todas as instâncias de consagração (prêmios, indicações da literatura especializada, principais organizações vinícolas, principalmente as francesas) seguem essa oposição entre vinhos de mesa ou regionais e vinhos de DOC. Tais instâncias adotam também a norma da impossibilidade de comparar vinhos de denominações diferentes (a excelência só pode ser reconhecida no interior de uma mesma denominação, como se pode perceber, por exemplo, quando da atribuição dos prestigiosos prêmios de Mâcon e do Salon Général de l'Agriculture). Essa construção histórica sui generis exerce um papel estruturante sobre a condição dos produtores, que, dependendo de sua posição na hierarquia socialmente instituída do valor dos vinhos, estabelecem uma relação diferenciada com as identificações geográficas instituídas e a sua notoriedade.

Ao realizar uma pesquisa sobre os processos de valorização dos vinhos num contexto de globalização (GarciaParpet, 2004), um artigo de 1987, publicado na Revue des Vins de France - periódico mais prestigioso do meio vinícola francês -, intitulado "Les vins du Midi deviendront-ils de grands vins?" chamou nossa atenção. Entre as "locomotivas do Midi vinícola que despertam", tal como são chamadas pelo autor, são mencionados dois produtores que "preferem a liberdade dos vinhos regionais, em detrimento das exigências dos DOC", e que "vendem tão caro seus vinhos regionais que causam inveja". ${ }^{6}$ Essa situação de forte valorização em um contexto de dupla classificação, ou seja, um vinho não DOC e proveniente de uma região vinícola tradicionalmente considerada como das mais desclassificadas da França, por oposição às regiões nobres de Bordeaux, Borgonha, Alsácia e Côtes du Rhône. Isso nos incitou a retraçar, a partir de entrevistas, a trajetória dessas duas "vedetes". A qualidade de ambas é considerada, no momento em que este artigo é elaborado, promissora, mas ao longo do tempo eles receberam avaliações muito diferentes. Tentaremos demonstrar em que a sua posição no espaço social e, principalmente, sua relação com os mercados regional, nacional e internacional foram decisivas na constituição e na gestão de sua fama, até mesmo no questionamento dos critérios de excelência dominantes no campo vinícola.

\section{Um nicho de mercado}

Filho de uma família do Roussillon que cultivou uvas há várias gerações e cujo pai tornou-se célebre por ter sido 
um grande treinador de rúgbi, F. V. fazia parte de um pequeno número de produtores conhecidos naquela região por fazerem um vinho tinto de qualidade, desde os anos 1960 e 1970. A região era renomada por seus vinhos suaves, naturais, classificados de DOC, legislação que não definia a qualidade dos produtos, mas alguns critérios de produção que podem propiciar uma produção de qualidade. ${ }^{7}$ Os vinhos tintos, por sua vez, eram classificados como "vins de table" ("vinhos de mesa"), segundo as normas em vigor. De fato, a grande maioria dos produtores fazia um vinho de consumo corrente, vendido a granel aos comerciantes.

Titular de uma propriedade familiar de 20 hectares situada em encostas, parte da qual constituída de solos reconhecidamente propícios à produção de vinhos de qualidade, F. V., seguindo o conselho de um consultor enólogo da Câmara da Agricultura com quem tinha forte relação, adquiriu técnicas de produção mais eficazes. Em 1968, ele foi um dos primeiros produtores da região a engarrafar vinho tinto e a fazer vin de garde, ${ }^{8}$ obedecendo a um critério de seleção draconiano que ele impôs a si mesmo. Seu vinho era consumido nos grandes restaurantes da região, onde adquiriu uma reputação que ainda hoje é lembrada pelos apreciadores e pelos profissionais do vinho. ${ }^{9}$ Os vinhos de F. V. eram conhecidos no mercado local, formado por residentes e turistas, pela propaganda de boca em boca, e a venda fora do Roussillon era feita essencialmente pela manutenção de uma lista de compradores assim também elaborada. O único estabelecimento parisiense que comprava seus vinhos era um restaurante catalão, o que constituía de certa forma uma variante do mercado local. Os clientes se referiam aos vinhos de F. V. como vin de Tresserre - comunidade na qual se encontra sua produção e onde ele era o único a fazer vin de garde, ou simplesmente "vin de V.".

Dois outros produtores do Roussillon rivalizavam, naquela época, em qualidade na produção de vinho tinto, sem o estabelecimento de critérios que permitissem classificá-los sem uma degustação comparativa. Até então, a qualidade dos vinhos era ligada a nomes de produtores, o que era uma informação suficiente para os conhecedores, e a categoria genérica oficial à qual pertenciam esses vinhos não era algo determinante para os consumidores. Do mesmo modo, a origem geográfica não era um elemento suscetível de estabelecer uma hierarquia para a produção desses viticultores de elite locais.

\section{Classificação e desclassificação}

Em 1977, uma parte dos vinhedos do Roussillon foi classificada como Côtes du Roussillon pelo INAO. Uma pequena parte dos vinhedos da região no norte de Perpignan, agrupados no vale do Agly, já conhecida pela qualidade da sua produção, recebeu uma classificação mais seletiva: Côtes du Roussillon-Villages. A produção de F. V., situada ao sul de Perpignan, foi categorizada como Côtes du Roussillon ${ }^{10}$ pelas autoridades daquele Instituto, o que colocava a sua produção no mesmo nível que a de seus colegas de uma grande parte dos vinhedos que não gozava, naquela época, de reputação tão elevada quanto a sua. Ao reivindicar a denominação Côtes de RoussillonVillages, F. V. recebeu uma resposta negativa porque era o único produtor em sua comunidade a pretendê-la, uma

Quadro 1 - As denominações de origem controlada (DOCs).

As instituições estabelecidas progressivamente na França, no fim do século XIX e no curso do século XX, desembocaram em um sistema de organização econômica que obedece a duas lógicas específicas. De um lado, a organização, pelo Estado, do mercado vinícola de massa, concernente aos vinhos de consumo corrente, sujeito a desequilíbrios estruturais da oferta que reside em um controle estreito da comercialização (controle da comercialização, obrigação de estocagem e de destilação). De outra parte, uma institucionalização que engendrou a criação de uma receita de denominação nos vinhedos com boa reputação pela criação das DOCs. Isso constitui uma forma de corporativismo na qual os profissionais chegam a dominar as condições de acesso ao selo e à regulamentação das condições de produção sem que o Estado intervenha diretamente na organização do mercado. Produzida em um contexto de fraude e de reação contra negociatas, a legislação sobre as DOCs e os vinhos de mesa cria dois mercados fortemente hierarquizados. Um decreto-lei de 1935 instituiu as DOCs e levou alguns produtores a produzir uma categoria de vinho legitimada pelo Estado, sob a autoridade de um Comitê Nacional das Denominações de Origem, transformado em Instituto Nacional das Denominações de Origem (INAO) em 1947. Seu princípio de seleção reside em grande parte em uma base territorial. Os decretos de reconhecimento elaborados pelas comissões de especialistas e aprovados pelo Comitê Nacional das Denominações Controladas controlam o direito de entrada na produção de qualidade, limitando o número de denominações, as superfícies consideradas aptas a produzir vinhos de denominação e aquelas que são efetivamente plantadas com vinha. 
vez que a noção de denominação, adotada pelo decreto de 1935, oficializava a idéia de "usos leais e constantes", referindo-se dessa forma a uma coletividade e não ao desempenho individual.

O estabelecimento dessas novas classificações trouxe prejuízos ao produtor, que se via assim desclassificado com relação aos seus colegas que gozavam da mesma reputação, sem que as propriedades intrínsecas dos produtos tivessem mudado. Por essa razão, ele decidiu ignorar a nova possibilidade de categorização que lhe permitiria ser mais bem colocado na hierarquia oficial e continuou a apostar na sua própria pessoa como garantia da qualidade de seus produtos, o que até então lhe havia assegurado uma clientela.

No início dos anos 1980, o filho de F. V. retomou a produção de seu pai. Estimando que ele pudesse ter dificuldades de se afirmar junto aos responsáveis por adegas e restaurantes, ele decidiu então obter formação como enólogo em Dijon, onde conheceu uma filha de agricultores da Borgonha, estudante de química e que havia também optado por aquela formação. Casados em 1991, os dois retomam a produção familiar e procedem a uma modernização do equipamento e da elaboração dos vinhos, com o cuidado crescente de pesquisar a clientela, todavia sem negar a identidade construída por F. V. e os seus resultados. Sua nora, que agora dirige sozinha a produção, após a morte de seu marido, explicita sua estratégia, levando em conta os trunfos que inspiraram os novos investimentos:

Somos conhecidos pelos vinhos de guarda, vinhos à base de carignan e de grenache, portanto, uvas que são verdadeiramente catalãs, e do vinho branco de uva macabeu, vinhos que envelhecem muito bem. É verdade que hoje há vinhos que podem evoluir pela produção de outros colegas, mas para a época dos velhos millésimes [milésimos $=$ anos das safras] de F. V., de 1970 e 1973... Recentemente bebemos alguns destes com enólogos, e todos ficaram estupefatos, pois tínhamos ainda um vinho que apresentava personalidade e potência. Com os vinhos de mais tradição, os vinhos de..., observavam-se misturas; assim, então, estamos dentro [dos critérios estabelecidos pelo decreto de reconhecimento dos Côtes de Roussillon]. A partir do momento em que se faz vinho $100 \%$ de grenache ou $100 \%$ de carignan, estamos fora; a partir do momento em que se reivindique os $100 \%$, isso não pode ser $\mathrm{AOC} \ldots$

Apesar de terem direito à denominação Côtes de Roussillon, pois sua produção está inserida na zona reco- nhecida pelo Comitê do INAO, as novas produções criadas pelo jovem casal são inspiradas por critérios diferentes daqueles da classificação oficial. Com efeito, nesse caso, considera-se que os vinhos monocasta ou varietais, elaborados a partir de uvas de uma única casta, e excluídos pela legislação oficial, que exige a combinação de castas, dão melhores resultados no que diz respeito à qualidade do vinho. Por essa razão, sua produção passa a ser classificada como "vinho regional" (vin de pays).

Questionada sobre a razão de suas escolhas, A., a nora do produtor, exprime sua posição com relação aos DOC:

Alguns dizem que estamos enganados, que com a notoriedade que temos e com os vinhos de qualidade que fazemos deveríamos então entrar na onda e depois dizer: vejam os Côtes du Roussillon, que bons produtos temos. Além disso, fazer também a promoção por nosso nome ${ }^{11}$. Mas penso que, como posso dizer?, no momento em que se deixar o produtor mestre na sua denominação com sua terra e suas uvas, e que se reconhecer que ele trabalha bem a ponto de deixá-lo livre para vinificar como ele entende, é isso aí!

A. supõe que o consumidor terá a oportunidade de provar seu vinho para ter uma opinião. Ora, veremos mais adiante que os consumidores de vinhos de qualidade, que constituíam uma elite que adquiriu uma prática precoce de degustação (fazendo parte dos "conhecedores", que adquiriram suas competências ao longo de uma familiarização lenta), e que tinham recorrido a uma institucionalização da prescrição mais tradicional por meio de redes (de boca em boca), tendem a diminuir. Ao mesmo tempo, uma clientela recentemente conquistada pelos prazeres do vinho é levada a dar atenção à classificação de experts para fazer as suas escolhas.

\section{Imposições institucionais e construção de uma coletividade de produtores}

Essa estratégia individual, que se choca contra a adotada pela imensa maioria dos produtores, é, apesar de tudo, sentida como uma desvantagem: "Estamos de fora, sabemos, alguns viticultores..., se pudesse ser comparado ao que é comparável..." (depoimento de A.). Durante alguns anos, o casal tentou contornar essa situação buscando estabelecer uma estratégia comum aos viticultores a fim de obter uma classificação mais gratificante: foi criada uma associação de oito adegas particulares da comunidade, que organiza festas e degustações para demonstrar a qualidade de seus vinhos e obter uma classificação, a qual, mesmo 
não contando com o termo "village", poderia se chamar "Côtes du Roussillon, les Aspres, Tressere" e seria assim mais distintiva.

Pode-se mensurar aqui o peso das restrições institucionais que levaram o casal a realizar investimentos necessários para conciliar uma reputação fundada sobre as exigências que um nome de produtor podia evocar e as exigências de uma legislação que privilegia o know-how coletivo em detrimento do empreendimento individual. Não é somente o tempo necessário para o alinhamento com o espírito do decreto de 1935 sobre as DOCs que chama a atenção, É necessário adicionar o tempo de constituição de um relatório de pedido de reconhecimento, sua aceitação pelo Comitê Nacional e a incerteza quanto ao sucesso da tentativa. Deve-se ressaltar também a especificidade do trabalho de harmonização da produção de diferentes viticultores, que é uma marca decisiva dos efeitos do direito sobre os investimentos econômicos.

Pautados numa reputação de várias décadas adquirida pelo pai, o jovem casal não sentiu de forma aguda a necessidade de obter uma clientela e de estar atento à transformação social sofrida pela demanda nesses últimos vinte anos, relacionada com a constituição de novas classes médias e estilos de vida. No campo vinícola, tais transformações favoreceram o aumento da importância da literatura de prescrição (Garcia-Parpet, 2003).

Na França, o consumo de vinho de mesa, que fazia parte da dieta cotidiana, diminuiu fortemente em favor de um consumo distintivo em festas e reuniões sociais, mudança expressa pelos profissionais da prescrição, como a passagem do "vinho-bebida" ao "vinho-cultura". ${ }^{12}$ Esses neófitos do consumo do vinho deparam com a oferta de um produto, objeto de distinção social, cujo valor e uso conhecem pouco. A transformação dos estilos de vida se manifestou também pela inovação nas formas de comercialização com o desenvolvimento da grande distribuição e da integração progressiva de produtos de luxo, provocando uma diversificação da oferta diante da qual esses novos consumidores se sentem despreparados. ${ }^{13}$ Devido à diversificação social da demanda de vinho, uma parte crescente dos consumidores tornou-se sensível aos conselhos de especialistas divulgados em livros ou em artigos especializados na imprensa. Essas obras de divulgação também são muitas vezes expostas por produtores na sala de degustação em sua propriedade, nos estandes dos salões e feiras em que eles participam, ou ainda reproduzidos nas correspondências enviadas ao cliente e em páginas da internet.

Ainda que preocupada em fazer conhecer o seu vinho e percebendo a importância dos signos de reconhecimen- to veiculados pela imprensa e por obras especializadas, A. faz alusão à pequena estrutura de sua propriedade e a sua viuvez recente, que a obriga a dedicar muito tempo aos filhos para justificar o pouco-caso que ela faz desses meios de valorização: "Sei que, a cada vez que tenho um artigo, é preciso fazer um livro de divulgação; é necessário que eu tenha tempo para isso". Essas classificações, oficiais ou não, são cada vez mais importantes, na medida em que os consumidores estão despreparados em matéria de cultura enológica.

A. lembra-se de ter contatado por duas vezes um importador norte-americano que lhe pediu amostras para encaminhar a Robert Parker, um especialista muito conhecido. Ela lhe forneceu as amostras mesmo sabendo que Parker jamais aceitaria seus vinhos. Esse guru dos vinhos aprecia realmente os vinhos boisés, ou seja, fortes, intensos. ${ }^{14}$ A. sabe que seus vinhos "estão de fora... inicialmente, as pessoas ficam um pouco reticentes. Isso vem do terroir, vem da maneira de vinificar, e preferimos trabalhar com os vinhos sedosos". Dito de outra forma, os V. não fazem parte dos produtores que têm tendência a "parkerizar" seu vinho para lhe dar um gosto mais forte, mais acentuado, cedendo assim ao desejo da demanda, uma atitude comercialmente rentável, pois as apreciações de Parker têm fama de "criar mercado". Os V. tendem a sacrificar os lucros comerciais em favor dos lucros simbólicos próprios ao campo vinícola.

Paralelamente à transformação social da demanda de consumo de vinho, ocorre uma transformação da oferta. A produção de vinhos de consumo corrente diminuiu muito em favor de uma produção de qualidade tanto no Roussillon quanto no território francês como um todo, e até mesmo fora da França. Essa melhora sensível da produção na região se deve a vários fatores: a política de reestruturação das vinícolas que foi adotada pelo governo nos anos 1970 (Temple, Touzard, Jarrige, 1996; Montaigne et al, 1997); o trabalho de alguns líderes de organizações profissionais convencidos da necessidade de uma produção de qualidade; as transformações sociais mais gerais no mundo do trabalho e dos estilos de vida que estimulam alguns executivos a se instalarem na região e se converterem em viticultores. Esses diferentes fatores mudaram as perspectivas de sucesso na profissão: a viticultura não é mais como nos anos 1970, uma profissão sem futuro, da qual os pais tentavam afastar seus filhos, dando preferência aos empregos urbanos. Hoje, as novas gerações investem na sucessão dos seus pais, e alguns, dentre os que haviam se afastado da produção familiar, a ela retornam.

Dotados de qualificações técnicas, adquiridas em cursos de enologia ou por intermédio dos serviços de profissio- 
nais, e de um capital cultural que lhes permite valorizar seus vinhos, esses produtores vêm pouco a pouco alcançando a excelência na denominação Côtes du Roussillon. Alguns deles atingiram a classificação 1er cru, ou 2ème cru, concedida pela Revue des Vins de France. Ainda que tais classificações não tenham nada de oficial e não estejam no mesmo plano das que foram instituídas na Exposição Universal de 1855 ou pelo INAO, constituem distinções às quais são sensíveis os consumidores e os produtores.

A. está plenamente consciente dessas transformações. Quando questionada sobre as possibilidades de exportação, ela responde que a maior parte de seus produtos é vendida na França. Ela se queixa de que os compradores estrangeiros perguntam primeiro o preço e nem provam o vinho, pois os preços praticados por ela são mais elevados que os dos vinhos pertencentes à mesma categoria não indicada pelos especialistas. A. nunca tentou valorizar seus vinhos em concursos internacionais. Ela está convencida de que, mesmo no exterior, os vinhos são classificados segundo as categorias oficiais francesas: "haverá sempre a noção de DOC".

Uma inserção de longo prazo no mercado internacional permitiu a outro viticultor, cuja trajetória será apresentada a seguir, estabelecer classificações mais favoráveis à valorização de sua produção. Da mesma forma que V., G. produz vinhos que pertencem à categoria "vinho regional". Mas outra posição no espaço social proporciona a valorização das suas terras com propriedades pedológicas idênticas às dos grands crus de Bordeaux, além de contornar a desvantagem de produzir seu vinho em uma das mais baixas categorias oficiais, e em uma região desvalorizada. Uma reputação construída em países anglo-saxões lhe permite conquistar o mercado francês, questionando os critérios de legitimidade instituídos.

\section{0 nascimento de um grande vinho?}

Antigo industrial produtor de finas luvas de couro, diplomado em Ciência Política e natural de Millau, onde foi presidente da Câmara de Comércio, A. G. foi atingido pela crise que se abateu sobre a indústria de peles da França nos anos 1960. Ele se dedicou à vinicultura, setor em que se revelou um produtor de talento, ainda que nada levasse a prever sua trajetória de sucesso.

No início dos anos 1970, já casado com uma mulher pertencente a uma família de classe alta e apaixonada por arqueologia, A. G. tornou-se proprietário de uma fazenda instalada em um antigo moinho romano, onde tradicionalmente se cultivava a policultura, na região de Hérault. Ora, Hérault era conhecida, a exemplo da macrorregião do Languedoc, como uma região vinícola desprestigiada. A.
G. lá descobriu, graças a Henri Enjalbert, um amigo, titular da cadeira de geografia na Universidade de Bordeaux e especialista em propriedades vinícolas, que uma parte de sua fazenda era constituída de terrenos excepcionais para a produção de vinho e adequada à produção de um grand cru. Ele aprofundou os conhecimentos sobre essa descoberta com o apoio de estudos geológicos. Convencido dessa possibilidade, A. G. se lançou na criação de uma vinícola que pudesse ser inscrita no que há de mais prestigioso nesse ramo. Assim, com uma propriedade dotada de solos que, segundo as especificidades pedológicas e o microclima, era propícia aos vinhos cujas características organolépticas são equivalentes àquelas dos melhores grands crus da Borgonha ou de Bordeaux, A. G. pretendia produzir o que os apreciadores chamam de grands vins (grandes vinhos).

Todavia, esse empreendimento não era simples. Um grande investimento era necessário para criar uma vinícola destinada a produzir um grand cru: plantar as vinhas, implantar toda a infra-estrutura adequada à fabricação de um grand vin e sua maturação, incluindo-se no cálculo o fato de que o vinho ganha valor só após vários anos da produção. Mesmo desprovido de capital financeiro durante um período turbulento de sua vida como empresário, A. G. dispunha de relações suficientes e de um profundo conhecimento de operações bancárias adquirido na gestão de uma empresa com 500 empregados para poder levantar os empréstimos necessários. Descendente de uma família de industriais que há várias gerações fornecia produtos para a corte da Inglaterra, A. G. era familiarizado com o consumo e a produção de luxo e suas respectivas exigências. Conseguiu transferir essa experiência para o universo da produção vinícola: escolhendo uvas nobres ${ }^{15}$ submetendo-se a parcos rendimentos, selecionando as colheitas, tendo uma atitude ascética para com os lucros imediatos e adotando as técnicas mais valorizadas.

Na verdade, A. G. buscou Émile Peynaud, o enólogo de maior reputação da época, conselheiro de um produtor tão renomado como o Château Margaux (primeiro cru classé de Bordeaux), para guiá-lo em seu trabalho de vinificação. ${ }^{16}$ Ainda que seu nome não conste no rótulo, sua participação é assim mencionada nos anúncios publicitários e na página da internet de A. G.: "Enólogo Émile Peynaud", "é muito raro para um enólogo assistir ao nascimento de um grand cru". Uma dupla distinção para esse produto sem comparação, elaborado por A. G., que sabia que estava na contramão de uma história de classificação que havia colocado o Hérault entre as regiões de piores posições da tradição vinícola. E essa posição tinha sido ratificada e moldada por disposições jurídicas. 


\section{Um produtor não alinhado com as classificações oficiais}

A propriedade onde se produz o vinho (terroir) não é constituída unicamente por suas qualidades geológicas e climáticas: é um espaço social e juridicamente reconhecido por possuir qualidades específicas. Foi a consideração da particularidade desse capital específico do campo vinícola que caracterizou o empreendimento de A. G. como uma "aventura". Uma operação que envolveu ao mesmo tempo esperança de grandes lucros e riscos enormes, tendo em vista o investimento necessário. É preciso levar em conta as trajetórias de cada um dos agentes participantes para entender a sua lógica.

Da parte de A. G., havia a temeridade de alguém que não tem mais nada a perder, aliada a uma ética do risco e uma afinidade com a produção de luxo. Evocando as mudanças ocorridas nas atividades econômicas, a mentalidade dos empreendedores e o surgimento de uma produção padronizada, A. G. afirma: "Não me curvei; segui firme apenas uma idéia: a de continuar a fazer o que eu fazia em Millau, isto é, fazer coisas boas, sendo o sucesso material uma consequência. Se esse belo trabalho permite que um entalhador, um carpinteiro de Paris, alguém que faz as mais belas luvas do mundo, enfim alguém que faz coisas bonitas, as façam para o papa ou para a rainha da Inglaterra, então é nesse espírito que eu trabalho...".

Para Émile Peynaud, a proposta de A. G. acontece em um momento em que a sua carreira, iniciada como laboratorista de uma casa de negócios em Bordeaux e alçada ao topo da consagração universitária, estava no apogeu quando da sua aposentadoria. Essa era uma "aventura", como ele relata numa entrevista ao jornalista Michel Gaillard, um trabalho de consultoria para o qual ele recusou remuneração, mas que eventualmente poderia lhe render um grande ganho simbólico: o de contribuir para o nascimento de um grand $\mathrm{cru}$, produzir em alguns anos aquilo que em outros lugares havia sido feito em muitos séculos (Peynaud, op. cit).

O caráter específico do capital enológico surgiu no momento da comercialização, pois apesar de uma produção que, do ponto de vista técnico, podia contar com todos os trunfos, A. G. relata a recusa generalizada que sofreram as primeiras safras:

Quando comecei a apresentar as minhas garrafas no mercado francês, ninguém queria comprar meus vinhos, dizendo: "Vinho regional do Hérault, não queremos isso!". Eles nem tiveram a bondade de degustar! Eu estava perdendo a cabeça porque havia feito a primeira colheita em 1978, e havia tentado na França. Descartado pelos agentes, descartado pelo mercado, era quase uma piada, em
1978, oferecer uma garrafa de Languedoc a 50 francos cada uma! Então, eu estava no limite... Houve o lançamento de alguns livros, um em inglês com um capítulo sobre meus vinhos e, em seguida, um livro inteiro da editora Christie's... Ainda que tudo isso acontecesse, eu estava no fundo do poço, na França, no nível oficial.

Enquanto F. V. tinha acesso apenas ao mercado regional ou nacional, sem conhecer o funcionamento do campo vinícola, com exceção do da França e da Bélgica, as relações internacionais de A. G. é que lhe permitem descobrir outras percepções e maneiras de legitimar seus vinhos. $\mathrm{Na}$ verdade, os países anglo-saxões têm uma concepção do vinho que não dá a mesma importância às características da propriedade (terroir), à história e ao direito. ${ }^{17}$ A literatura de prescrição que se desenvolveu nos anos 1960 para informar os consumidores desprovidos de cultura enológica produziu classificações que obedecem a outros critérios: os prêmios instituídos e as degustações, que não respeitam as delimitações geográficas impostas pelas DOCs, nem mesmo a distinção entre DOC e outras categorias de vinhos. Os produtos de A. G., que se encontravam sem alinhamento no mercado francês, obtiveram um lugar de destaque primeiramente no mercado inglês, e em seguida em numerosos países, adquirindo uma reputação internacional.

\section{"Uma reputação mundial anglo-saxônica"}

De fato, é a vocação internacional, mais precisamente inglesa, das atividades anteriores de A. G. e o capital social correspondente que vão propiciar a valorização de seus vinhos. Não tendo sucesso junto aos comerciantes de vinhos e responsáveis por adegas francesas, ele se vê impossibilitado de recorrer à clientela que havia conseguido como industrial do couro com vocação exportadora para fazer frente aos seus problemas financeiros. Foi pela mediação de um dono de restaurante inglês, comerciante de vinho, que ele acabou se tornando conhecido pelos especialistas no mercado anglo-saxão. Estes colocaram seus vinhos no mesmo plano que o Château Lafite e o Château Latour (dois premiers crus classés de Pauillac, no Médoc) ou, ainda, que o Pétrus (vinho mítico de Pomerol). Dito de outra forma, classificado ao lado daqueles que ocupam o topo da hierarquia dos vinhos franceses, associando dessa maneira a origem geográfica e as classificações mais prestigiosas. Os vinhos de A. G. foram mencionados pelos críticos mais famosos da Inglaterra como também dos Estados Unidos, o que suscitou artigos, capítulos de livros e mesmo um livro inteiro tendo como autor o chefe do departamento de vinhos da editora Christie's (Mackenzie, 1995). 
A. G. relata como o fato de ser reconhecido por um prestigioso profissional do vinho acarretou menções de outros profissionais:

Um famoso dono de restaurante (e comerciante de vinho) nos convidou em seguida para ir a Londres. Impensável! Um simples filho de Aveyron, de repente recebido em Londres com sua mulher em um jantar em que havia tudo de bom para um francês do Languedoc. Não penso que isso aconteceria hoje porque há muitas coisas bizarras, mas naquela época um vinho do Languedoc que tinha a estatura de um Château Latour... Isso era realmente algo de extravagante, o primeiro jantar foi impressionante, tive a sensação de... A partir do momento em que os jornais ingleses dizem alguma coisa sobre você... foram lançados dois livros... Constituiu-se num sucesso mundial anglosaxão, foram os maiores conhecedores ingleses de vinho, como Hugh Johnson, ${ }^{18} \mathrm{Oz}$ Clark, Michael Broadbent, que nos colocaram em órbita.

Após essa explosão, A. G. utilizou seus conhecimentos do mercado anglo-saxão para valorizar seu know-how e o de outras vinícolas do Hérault. Ofereceu seus serviços a duas cooperativas, propondo a vinificação de seus vinhos com a condição de que elas obedecessem a um conjunto de normas rigorosas. Em 1993, o vinho Figaro, da cooperativa de Villeveyrac, assinado como Daumas Gassac, foi eleito o vinho do ano pelas revistas Wine e Sunday Telegraph. É esse vinho e suas distinções que figuram em nome de A. G. na publicação Who's Who International Vins et Spiritueux, de 1996.

Uma "notoriedade mundial", entretanto frágil, já que não conta com o reconhecimento da França, que, malgrado o crescimento espetacular dos vinhos de qualidade provenientes do Novo Mundo, conserva sua hegemonia no conjunto dos grands vins. Será preciso esperar oito anos para que o sucesso obtido nas classificações anglosaxônias tenha efeito no interesse dos especialistas franceses. Podemos citar, por exemplo, o artigo sobre o "Mas de Daumas Gassac" publicado na Revue des Vins France em 1993, por Pierre Casamayor - mestre de conferência em climatologia e pesquisador no laboratório de enologia da Faculdade de Farmácia de Toulouse, autor de numerosas obras de popularização sobre vinhos e eaux de vie. "A qualidade do solo é uma dádiva das fadas", para citar apenas um dos elogiosos comentários que compõem o referido artigo. Uma consagração para o empreendimento de A. G.

Essa menção elogiosa não é somente um efeito da prescrição estrangeira na prescrição francesa, mas o efeito conjugado da constituição de um campo enológico no Sudeste, par o qual a literatura especializada contribuiu significativamente. Observam-se efeitos cruzados de políticas públicas destinadas a reestruturar a produção vinícola para promover uma produção de qualidade e de inovação institucional. Assim, busca-se implantar normas de produção exigentes (limitação de rendimentos, etc.), como também evitar as conseqüências negativas de uma má reputação e criar, para além do Atlântico, um mercado que permita uma valorização dos vinhos do Languedoc (empregando as classificações anglo-saxônias, que se baseiam nas uvas utilizadas). A introdução de uvas nobres na região, principalmente merlot e chardonnay, e de uma classificação oficial que permitiu mencioná-las no rótulo contribuiu para a revalorização dos vinhos do território. Essa nova maneira de conceber o produto, aliando o rigor na qualidade a uma chave de leitura para os consumidores habituados a distinguir os vinhos pelas uvas, proporcionou uma resposta direta às demandas do mercado estrangeiro, principalmente do norte-americano. A experiência de A. G. esteve na origem de um movimento de chegada ao Languedoc-Roussillon de diversos empresários em busca de conseguir uma produção de excelência, aproveitando o baixo preço das terras e apostando na recomposição dos valores da excelência. $\mathrm{O}$ caso mais emblemático e noticiado pela imprensa é sem dúvida a tentativa abortada de Mondavi - um dos produtores norte-americanos mais famosos, terceiro colocado no mercado dos Estados Unidos e que também produz vinhos no Chile, em parceria com a Baronne de Rotschild - de se instalar em terrenos vizinhos à propriedade de A. G. ${ }^{19}$

Impulsionado pelo seu sucesso no mercado anglo-saxão e pelos sinais de reconhecimento emitidos pela literatura francesa especializada, A. G. alterou seus investimentos, direcionando-os para o mercado francês. Adotou várias práticas: freqüenta as exposições que acontecem na França, incentiva a criação de uma exposição em Aniane comunidade onde está situada a sua vinícola -, estimula a melhoria da qualidade da produção na região dando conselhos aos produtores, cuida da imagem na sua adega de degustação, onde são expostos todos os artigos da imprensa e todos os prêmios obtidos. No passado, em torno de $90 \%$ da produção era exportada, " $85 \%$ da distribuição ia para o mundo anglo-saxão e de 10 a 15\% para amigos pessoais, já que no couro e na costura eu tinha muitos amigos; veja que isso durou até mais ou menos 1985 e 1986, o momento em que grandes compradores franceses vieram, por exemplo o grupo Nicolas... Então, esses são os dois grandes eventos, os ingleses em 1978 e oito anos depois Nicolas, nos colocaram em 400 vitrines na França". Atualmente, as vendas na França e no exterior estão próximas da igualdade. 


\section{Um produtor de vanguarda}

Nesse contexto, A. G. surge com um dos pretendentes a questionar os esquemas de produção e de avaliação impostos pelas instituições dominantes no campo enológico na França. Sua página na internet apresenta inicialmente o contraste entre a posição inferior da categoria na qual ele é obrigado a declarar seu vinho e a notoriedade mundial promovida pelos especialistas: a frase "um vinho regional que não tem a menor denominação oficial teve a honra de ser colocado junto aos maiores vinhos da França" é seguida de todas as menções de elogios dos especialistas: "um dos dez melhores vinhos do mundo" (Michael Broadbent), "excepcional" (Robert Parker), "maior grand cru" (Oz Clarke), "único grand cru do Midi" (Hugh Johnson).

Essa distância com relação às denominações tem a tendência de se afirmar junto a numerosos produtores. Uma seleção dos 165 "melhores viticultores do LanguedocRoussillon", estabelecida pela demanda das organizações profissionais regionais, apresenta um quadro onde 13\% de propriedades produzem vinhos regionais, 32\% produzem ao mesmo tempo DOC e vinhos regionais e 55\% produzem DOC. Um artigo publicado na Revue des Vins de France em abril de 1994, intitulado "Movimente suas papilas", é revelador dessa liberdade com relação às referências oficiais:

As denominações locais não respondiam de maneira totalmente satisfatória às ambições dos produtores e aos desejos dos consumidores. É uma regra econômica universal e inclusive saudável a que incentiva os homens a encontrar outras oportunidades comerciais, outros produtos quando sua produção habitual sofre com vendas abaixo do previsto. Assim como um viticultor de Saint-Émilion ou de Sancerre não sonharia em fazer vinho regional, um ambicioso do Languedoc pensará encontrar nisso sua salvação. Mas as considerações econômicas não são as únicas envolvidas: há também a rigidez dos textos que regulamentam a utilização das uvas nas denominações. Em nome de uma pretensa "salvaguarda de uma tipicidade", as vinícolas do LanguedocRoussillon, do Loire, do Sudoeste foram interditadas, pelo menos foi limitada a implantação das uvas que surgem no mundo inteiro como fontes de sucesso. Desse modo, não devemos nos surpreender com o fato de os vinhos regionais - nos quais as uvas são largamente autorizadas - servirem de porta de saïda para os produtores que desejam realizar grandes vinhos.

\section{Questionamento dos critérios de excelência}

A. G. tenta impulsionar uma revolução específica no campo enológico, buscando minar os antigos princípios de produção e avaliação, e criando um estilo que toca no ponto fraco dos valores dominantes: ele se inscreve em uma corrente de vanguarda que considera o cuidado com o meio ambiente e a qualidade sanitária dos produtos como novos critérios de excelência.

Como numerosos produtores do interior do Languedoc, ele é dotado de um capital singular: os vinhedos cobrem apenas uma parte das terras da região, sendo o restante coberto por vegetação agreste, o que lhe permite praticar uma vinicultura biológica baseada no ecossistema, maneira de produzir que as outras regiões não podem praticar. É uma forma de obter uma espécie de originalidade geográfica (portanto, não reprodutível) em uma corrente de vinicultura que aposta na produção biológica e que se desenvolve nestes últimos anos à margem das instituições oficiais. Ele assim apresenta sua propriedade: "Um espaço de 80 hectares com uma superfície de vinhas de 40 hectares, mantendo-se o restante como floresta. Superfície total das florestas que circundam as vinhas: 1.500 ha". Uma particularidade é destacada pela Revue des Vins de France: "As vinhas estão em nichos nas clareiras, no meio das árvores e do agreste, um verdadeiro patchwork entre uma produção humana e uma natureza deixada em estado selvagem". Essa imbricação apresenta uma tripla vantagem: "O frescor e a umidade do ar fornecidos pela floresta, um ambiente marcado pelo odor da floresta e pelo respeito à vida selvagem, pássaros, insetos, que ajudam a equilibrar o vinhedo" (R. V. F., nov. 1993, p. 58). A. G. ressalta o fato de ter plantado mudas de antigas vinhas do Médoc anteriores a 1914, recusando a clonagem - uma técnica de seleção das plantas generalizada pelos produtores e admitida pelas instituições oficiais: "Comprei mudas de vinhas-mães, não clonadas. Recuso as extravagâncias modernas: na produção de carne, o clone acaba em vaca louca; na vinicultura, em vinho industrial" (entrevista concedida a A.-M. Schaller, do Midi Libre, em 17 de novembro de 1998).

Enfim, A. G. revaloriza as uvas locais que a política nacional de revalorização da região vinícola havia condenado à extinção. Essa ruptura só é possível porque a mudança se efetua, de certa maneira, em uma continuidade e fazendo valer os elementos de um capital dos mais legítimos, a saber, uma propriedade equivalente às melhores propriedades da região de Bordeaux, uvas nobres e uma vinificação "clássica medocana" [do Médoc]. Como na religião, lembra-nos Weber, os novos profetas brotam dos corpos dos padres. Foi o capital de autoridade e de relações que A. G. adquiriu, produzindo vinhos no puro estilo de Bordeaux, que lhe permitiram propor um novo tipo de vinho sem se arriscar a sofrer uma condenação radical, transformando suas audácias heréticas em traços de vanguarda. ${ }^{20}$ É esse 
o termo que é empregado para designar a produção de A. G. e de outros produtores do Languedoc-Roussillon, que "podem doravante fazer concorrência séria aos de Bordeaux e da Borgonha" (Cap. "Sur l'avant garde", Revue des Vins de France, set. 1987, p. 43).

O Languedoc-Roussillon, com sua "star incontestável", tornou-se uma região pioneira. Essa nova forma de construir a qualidade tem uma forte influência na crise da produção vinícola francesa iniciada na virada do século. Apoiando-se no desempenho dos produtores do Languedoc-Roussillon, outros produtores situados em regiões mais nobres questionaram a legitimidade das classificações DOC, reivindicando as classificações por tipos de uvas e enaltecendo as marcas. Instaurou-se o debate no seio do INAO e do Parlamento, que organizou, em 2003, um colóquio intitulado "Vinhos da França: uma cultura em movimento, a exceção francesa em debate".

\section{CONCLUSÃO}

O exame das duas trajetórias revela a importância dos quadros institucionais para a análise dos mercados, ao mesmo tempo em que ressalta que não se pode prescindir da sociologia do agente para compreender sua dinâmica. Os dois personagens não têm o mesmo capital, a mesma posição no espaço social, nem a mesma história, e não vão reagir da mesma maneira em face das classificações instituídas e das transformações concernentes.

Os descendentes do primeiro produtor tentam se conformar às classificações das DOCs, uma atitude que pode parecer ultrapassada quando as classificações oficiais não são mais, em si mesmas, um sinal de raridade: o número de DOCs foi multiplicado por dez desde a sua criação, em 1935; a superfície considerada apta a corresponder aos critérios estabelecidos aumentou consideravelmente; o selo inicialmente reservado aos vinhos e às águas minerais é igualmente atribuído a um bom número de produtos alimentares. Nesse contexto, as classificações oficiais tornam-se menos distintivas que os prêmios e as menções nos guias e revistas especializados.

Para o segundo produtor, a conjunção de diversos elementos (forte capital cultural aliado a um vinhedo sui generis; não alinhamento às classificações oficiais; boa posição na economia dos produtos de luxo) lhe permite beneficiar-se de classificações que lhe são favoráveis e não somente tornar-se um produtor de elite, mas também enfatizar uma nova forma de pensar a excelência, modificando o campo das possibilidades. O que é único no caso de A. G. não é tanto sua competência em maximizar seu resultado em um contexto de mercado já estabilizado, mas a competência de questionar um enquadramento de mercado e levar à cena política os elementos de uma nova construção social do mercado da excelência.

\section{NOTAS}

${ }^{1}$ Conforme, dentre outros, Pierre Bourdieu (1997) e Neil Fligstein (2001).

${ }^{2}$ Segundo Gilbert Garrier e Philippe Rouquié, uma hierarquia qualitativa atestada pela reputação adquirida e também pelo nível de preços surgiu há vários séculos (Garrier, 1998; Rouquié, 1988).

3 Denominação de Origem Controlada (nota do tradutor).

${ }^{4}$ A supremacia dos vinhos de Bordeaux pode ser objetivada a partir do número de obras que thes são dedicadas, ou ainda pelo lugar de escolha que lhes é reservado nos cursos de degustação.

${ }^{5}$ Os vinhos do Midi tornar-se-ão grandes vinhos? (Nota do tradutor.)

${ }^{6}$ Não dispomos de todos os preços daquela época. Por outro lado, um dos produtores citados vendia seus vinhos jovens por 150-200 francos a garrafa, entre 1997 e 1999.

${ }^{7}$ Os critérios variam segundo as denominações, suscetíveis de revisão por um acordo do Comitê Nacional do INAO. Tais critérios referem-se às uvas utilizadas, à maneira de plantar e de cortar as videiras, à vinificação (produtos utilizados), por vezes também à colheita (especificando o manuseio). O selo é concedido a cada colheita, após um teste químico e, mais recentemente, organoléptico.

\footnotetext{
8 "Vinho de guarda", termo comumente atribuído aos vinhos mais consumidos e que atingem seu "apogeu" após vários anos, condição essencial para fazer parte dos grands vins - categoria não oficial que evoca a hierarquia que vai dos vinhos de mesa aos grands crus, sendo que os grands vins se situam no topo dessa hierarquia.

${ }^{9}$ Conforme principalmente o Guide Hachette 97 , que qualifica a produção como "vinícola tradicional de elevada reputação" (Guide Hachette 97).

${ }^{10}$ Entre outras condições requeridas para obter o selo "Côtes du Roussillon", os vinhos rosés e tintos devem ser obtidos a partir de várias uvas (carignan noir, grenache noir, lladonner pelut, cinsault, syrah, mourvèdre e macabeu)

${ }^{11}$ Mesmo dentro de uma denominação, a reputação dos produtores varia sensivelmente. Cada um pode concorrer com preços que são organizados na França entre os produtores de uma mesma denominação.

${ }^{12}$ Segundo uma publicação do INAO, o consumo de vinhos AOC (DOC) por habitante foi multiplicado por três em 30 anos: "Uma vitória francesa: a denominação de origem controlada" (INAO, sem data).
} 
${ }^{13}$ Em 1978 os supermercados Leclerc e Auchan lançaram simultaneamente feiras de vinhos nas suas sucursais contando com grands crus como chamariz. Nos anos 1990, várias outras redes replicaram esse tipo de promoção (Montaigne, 1999).

${ }^{14} \mathrm{O}$ termo boisé, empregado pelo autor, significa "amadeirado" e foi interpretado aqui como forte, intenso, de gosto bastante acentuado. (Nota do tradutor.)

${ }^{15}$ Cabernet-sauvignon, merlot e cabernet franc.

${ }^{16}$ Émile Peynaud relata essa experiência de consultoria numa sequência de entrevistas dada a um jornalista (Peynaud, 1995).

${ }^{17} \mathrm{O}$ artigo, consagrado mundialmente no livro The Oxford Companion of Wine, resume bem a diferença de abordagem na fabricação do vinho, com relação aos países tradicionalmente produtores: "No Velho Mundo, onde há séculos de tradição, a natureza é determinante, ela é uma força motriz. No Novo Mundo, a natureza é vista com suspeição, um inimigo que deve ser controlado, dominado pela ciência em seus mínimos detalhes" (Robinson, 1999). Essa diferença se exprime tanto nos termos utilizados para se referir aos vinhos dos países tradicionalmente produtores como para aqueles do Novo Mundo: vinhos de propriedades/vinhos tecnológicos.

${ }^{18}$ Hugh Johnson é, sem dúvida, o autor inglês mais conhecido.

${ }^{19}$ Conforme Torres, 2005

${ }^{20}$ A propósito da alta costura, Pierre Bourdieu analisa que a mudança se faz na continuidade, e os estilistas de vanguarda têm mais chances de sucesso quanto mais pertençam às grandes maisons (Bourdieu, Delsaut, 1975).

\section{REFERÊNCIAS}

BOURDIEU, P. Le champ économique. Actes de la Recherche en Sciences Sociales, n. 119, p. 48-66, set. 1997.

BOURDIEU, P.; DELSAUT, Y. Le couturier et sa griffe. Actes de la Recherche en Sciences Sociales, v. 1, n. 1, p. 7-36, 1975.

DOUGLAS, M. How Institutions Think? London: Routledge \& Kegan Paul, 1987.

\section{Traduzido do francês por Maurício Serva.}

Artigo recebido em 30.06.2005. Aprovado em 24.01.2007.

\section{Marie-France Garcia-Parpet}

Pesquisadora do Institut National de la Recherche Agronomique. Mestre e Doutora em Antropologia Social pelo Museu Nacional na Universidade Federal do Rio de Janeiro. Interesses de pesquisa nas áreas de antropologia e construção social do mercado. E-mail: garciat@ivry.inra.fr Endereço: INRA/TSV, 65 Boulevard de Brandebourg, IVRY-SUR-SEINE, 94205, França.
FLIGSTEIN, N. The Architecture of the Markets. Princeton: Princeton University Press, 2001

GARCIA-PARPET, M.-F. Style de vie et manière de boire: un marché de l'offre des biens de prescription œenologique. Cahiers Lillois d'Économie et de Sociologie, juin 2003.

GARCIA-PARPET, M.-F. Le marché de l'excellence, les grands crus face à la mondialisation des marchés. Genèses, n. 56, 2004.

GARRIER, G. Histoire sociale et culturelle du vin. Guide Hachette 97. Larousse-Bordas, 1998.

INAO. Une réussite française: l'appellation d'origine contrôlée (sem data).

LACHIVER, M. Vins, vignes et vignerons, histoire du vignoble français. Paris: Fayard, 1988.

MACKEnZIE, A. Daumas Gassac: The Birth of a Grand Cru. Prefácio de Émile Peynaud. Kingston- upon-Thames, UK: Segrave Foulkes / Christie's Wine Publications, 1995.

MONTAIGNE, E. et al. Les mutations du négoce des vins tranquilles en France. COLLOQUE DE LA SFER SUR LA GRANDE DISTRIBUTION ALIMENTAIRE. Anais. Montpellier, 22-23 mai. 1997. p. 122-135.

MONTAIGNE, E. Trabalho apresentado no workshop "Market, right and equity: rethinking food and agricultural grades and standards in a shrinking world". Ifas (Institute for Food an Agricultural Standards). out./nov. 1999. Michigan State University, 1999.

PEYNAUD, E. Enologue dans le siècle, entretiens avec Michel Guillard. La Table Ronde, 1995.

ROBINSON, J. (Org.). The Oxford Companion of Wine. Oxford: Oxford University Press, 1999.

ROUQUIÉ, P. Vignobles et vignerons du Bordelais (1950-1980). Éditions du CNRS, 1988.

TEMPLE, L; TOUZARD, J. M.; JARRIGE, F. La restructuration des coopératives vinicoles en Languedoc-Roussillon: du modèle communal à la diversité des adaptations actuelles. Revue de l'économie méridionale, v. 4l, n. 163, p. 45-63, 1996.

TORRES, O. La guerre des vins: l'affaire Mondavi: mondialisation des terroirs. (Em colaboração com Dorothée Yaounnc.) Paris: Dunod, 2005. 